\title{
Eddy Current Probe Configuration for Full Rail Top Surface Inspection
}

\author{
Anouaressadate Aouf $^{1}$, Tarik Bouchala ${ }^{2,3}$, Abdelhak Abdou ${ }^{2,3^{*}}$, Bachir Abdelhadi ${ }^{4}$ \\ ${ }^{1}$ Electrical Engineering Department, Kasdi Merbah University, Laboratory of Electric Engineering, Ouargla 30000, Algeria \\ ${ }^{2}$ Electrical Engineering Department, Mohamed Boudiaf University, M'sila 28000, Algeria \\ ${ }^{3}$ Research Laboratory on the Electrical Engineering, Mohamed Boudiaf University, M'sila 28000, Algeria \\ ${ }^{4}$ Laboratory of Electric Traction Systems (LSTE), Electrical Engineering Department, Batna 2 University, Batna 05078, \\ Algeria
}

Corresponding Author Email: abdelhak.abdou@univ-msila.dz

\section{https://doi.org/10.18280/i2m.200201}

Received: 3 December 2020

Accepted: 12 March 2021

\section{Keywords:}

eddy current, nondestructive testing, rail, multidifferential probes

\begin{abstract}
In this paper, we have carried out an experimental study of the detection of top rail surface cracks. Firstly, we have highlighted the inability to inspect the entire rail head surface by a single sensor with a single scan. To overcome this inspection inability, we have proposed a multisensor system composed of three differential probes arranged within a specific configuration. The yielded results showed the efficiency and the robustness of the proposed configuration in the detection of cracks regardless its size, orientation and location.
\end{abstract}

\section{INTRODUCTION}

As the modern science and technology are advancing rapidly, the rail technology is also following and developing at high speed, the rail is basically applied to railway, the importance of regular inspections of railway tracks is increasing day by day. It is becoming more and more important to ensure a safe operation of railway traffic. In fact, the timely and effective maintenance of defective rails can greatly reduce the occurrence of traffic accidents [1]. Rail defect is one of the most important reasons for track degradation, and how to ensure the rail safety and reliability becomes a significant problem for railway system [2].

The degeneration of rails is increasing due to the constant increase in loads and amount of overall traffic. In particular, the operation of high speed trains, the alteration of materials used in the wheel sets and the application of modern drive system concepts result in an increasing number of flaws in rails. This causes a change in the damage mechanism by the modern rolling stock and may alter the appearance of different flaw types.

To guarantee a safe operation of rail traffic, mechanized non-destructive inspection techniques are used in large scale to detect damages on rails [3]. Eddy current inspection is a well-established and reliable electromagnetic method for detecting cracks in conducting materials. It is often used to locate cracks in pipes, rivets and rails, but it can also be used for material identification or measuring dimensional deviations $[4,5]$. The sensitivity of eddy current testing makes it a promising technique for detecting small cracks in the surface of a rail. Cracks which are less than about $5 \mathrm{~mm}$ in depth are of particular interest, because ultrasonic testing cannot be used to evaluate this type of cracks being so close to the surface $[6,7]$. The use of multicoils eddy current (EC) sensors in non Destructive Testing (NDT) provides high speed inspection and can make a measurement of large surfaces. Furthermore, it permits to reduce noise and provides more information about the defect characteristics $[8,9]$. In this work, we shall cope with the detection of defect in U50 rail surface by using one probe operating in differential mode. In this study, we shall test by finite element numerical simulation the applicability of the proposed multi-elements probe.

\section{ORIGINS OF DEFECTS IN RAILS}

Historically, in railroad industry, the term 'defect' has been associated with some visible artifacts, e.g., fissures developed during service. Customarily, in physical metallurgy this term is used in relation to crystallographic imperfections such as dislocation and stacking, Figure 1. This has been mentioned in order to avoid confusion in the use of the term in two entirely different contexts. Defects may form intrinsically during processing or may be initiated during service. These are accordingly classified as material defects and service defects, respectively [3].

In the following study, we create artificially two kind of surface defects placed on top U50 rail surface.

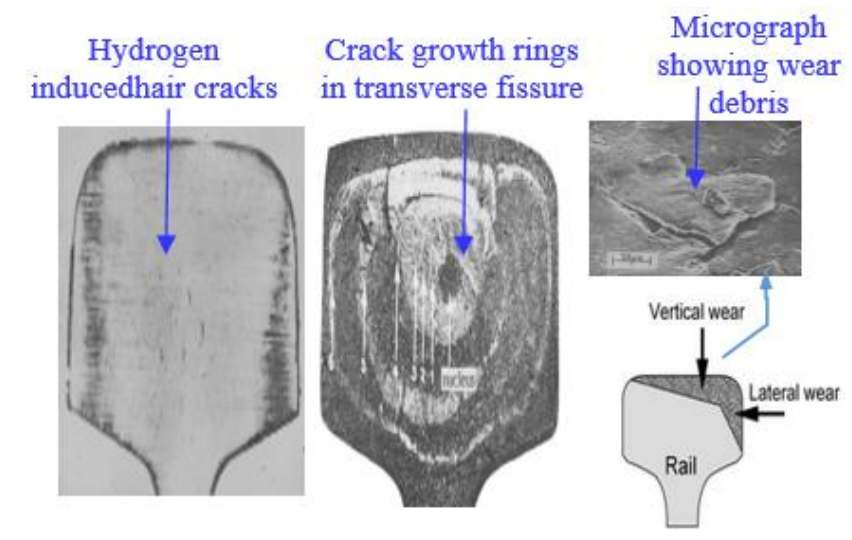

Figure 1. Material and service defects 


\section{EXPERIMENTAL TEST BENCH}

The designed and implemented experimental test bench is composed by two main units: an electronic control drive and a mechanical part insuring the displacement of the probe as shown in Figure 2.

This experimental test bench fulfills principally three tasks:
- Detection by EC differential sensor connected to impedance analyzer Zscope.

- Data acquisition and visualization in PC via the installed WinEC ${ }^{\text {TM }}$ software.

- Aduino, stepper motor and its $\mathrm{H}$ Bridge to rotate EC sensor around the rivet head.

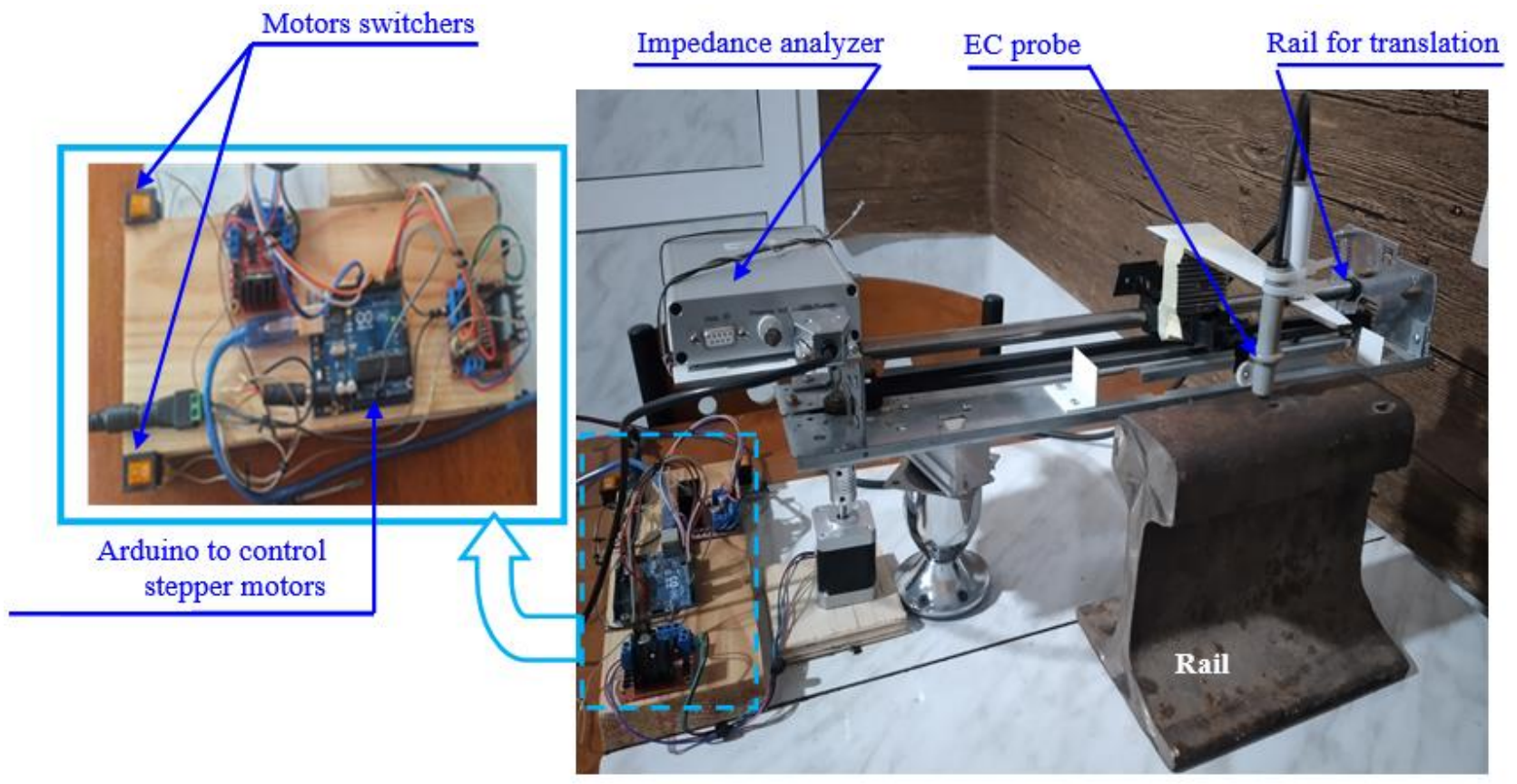

Figure 2. Experimental test bench

\subsection{EC differential probe}

The classical differential probes consist of two coils that compare two adjacent zones of the inspected material. The detecting coils are wound in the opposite directions to one another in order to equalize the induced voltages originated by the excitation primary field $[10,11]$. The output voltage of the differential coil probe is zero when there is no crack. Differential coils have the advantage of being able to detect very small discontinuities and eliminate the external disruptions such as velocity, temperature and lift-off change. Therefore, this sensor is more adapted to the detection of cracks in railway (Figure 3 ).

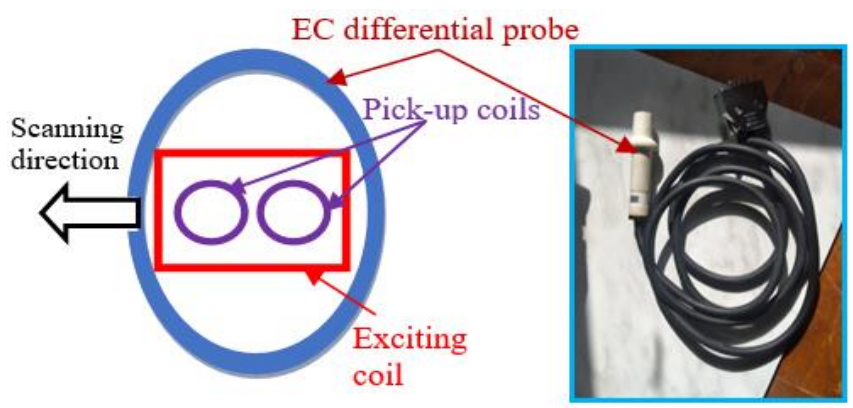

Figure 3. Blarow-D differential probe

\subsection{U50 Rail}

The tested rail U50 presents transverse and longitudinal cracks. So, to study the probe sensitivity according to defect position and orientation, the three artificial cracks are positioned following transverse and longitudinal directions, Figure 4.

\subsection{Impedance analyzer and data acquisition with WinECTM}

The Z-Scope v6.2 includes an excitation signal generator and a multiplexed two receiver channels, Figure 5. The signal generator produces a sine wave up to $100 \mathrm{kHz}$ to stimulate an external circuit. The receiver has two multiplexed differential channels. The synchronous detector permits to determine the real and the imaginary parts of the input signals (determine the obtained signal amplitude and phase).

\section{INSPECTION DEVICE SETUP}

The EC inspection follows through four steps:

- Judicious fixing of geometric parameters such as Lift-off, horizontality of the inspected rail and the verticality of the sensor probe.

- Setting the motor speed by setting the number of steps per revolution via an Atmel 8-bit AVR microcontroller Arduino board and a L298N motor driver.

- Choosing the exciting field frequency and displaying the parameters of the Z-Scope WinEC TM acquisition interface.

- Once all these parameters are set to the desired values, Motor 1 is activated. Then, the resistance, the reactance and the Lissajous curves are displayed on the corresponding windows of WinEC. TM installed on PC. 

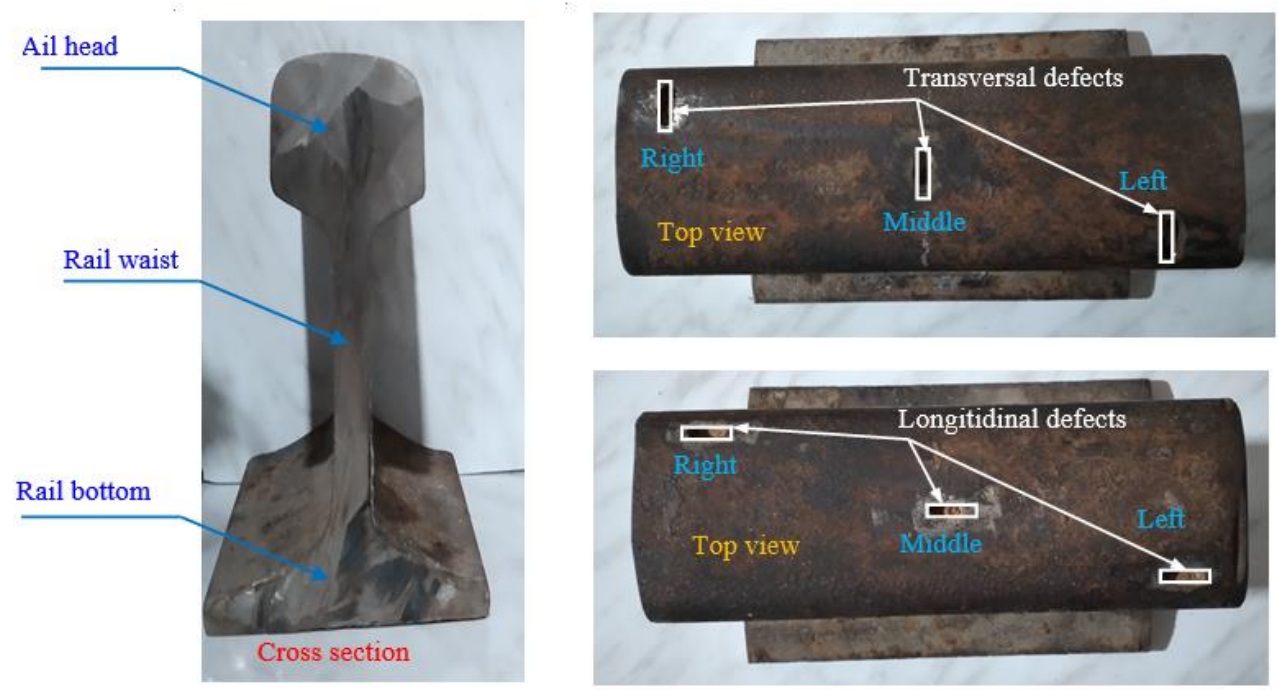

Figure 4. U50 Rail head with three transverse and longitudinal artificial defects

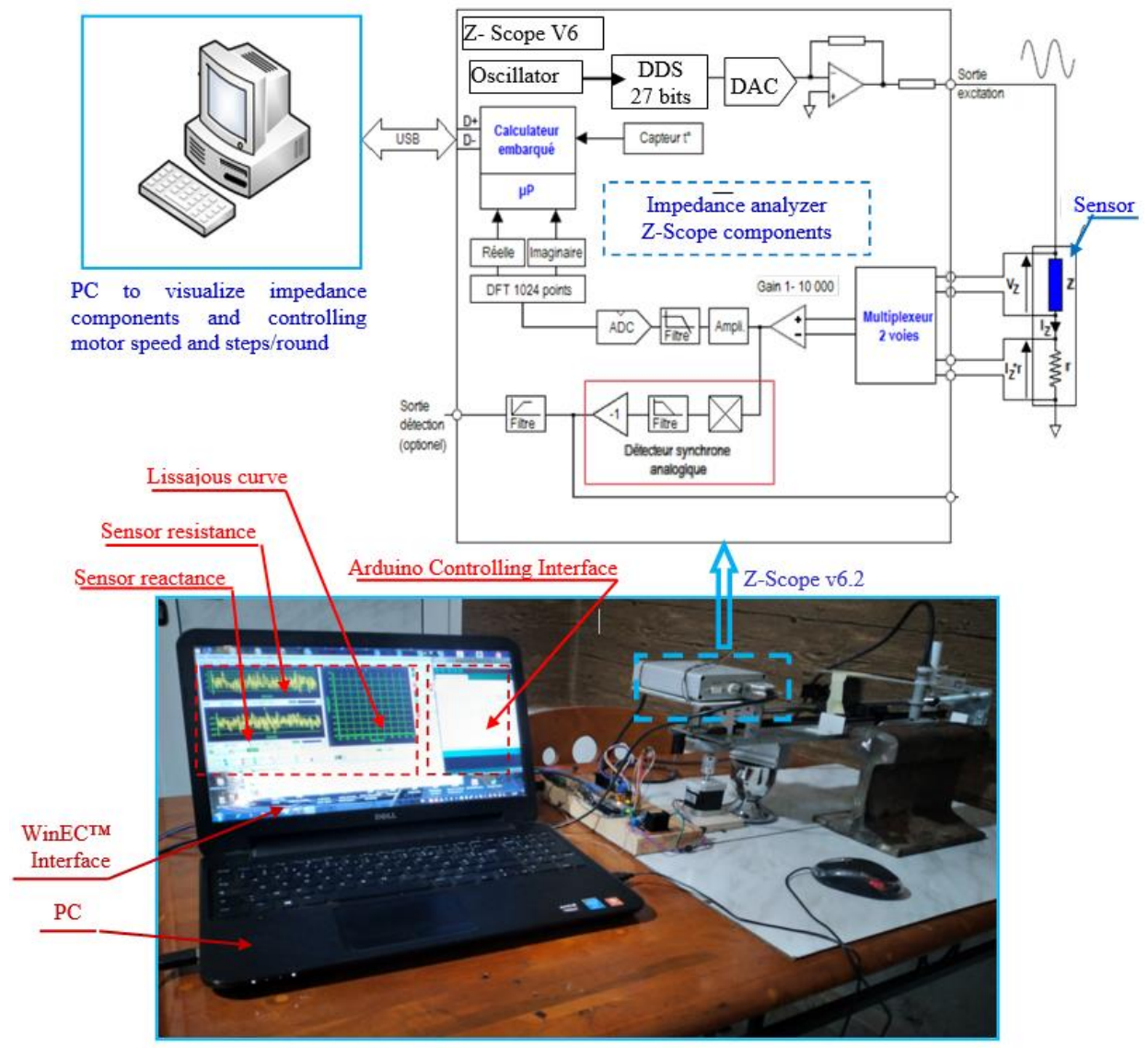

Figure 5. Impedance analyzer and data acquisition with WinEC ${ }^{\mathrm{TM}}$ under PC

\section{DETECTION OF TRANSVERSE AND LONGITUDINAL CRACKS}

Figure 6 and Figure 7 show, for $100 \mathrm{kHz}$ and $10 \mathrm{kHz}$, the sensor impedance components when the probe moves following the left, the middle and the right rail top surface for transverse and longitudinal cracks.

From the obtained results, we can conclude that the probe detects only the crack when it is positioned on its path. On the other hand, a high frequency is more adapted because the cracks are on the surface; and the resistance amplitude from pick to pick fluctuates from $90 \Omega$ to $550 \Omega$ when the exciting field frequency changes from $10 \mathrm{kHz}$ to $100 \mathrm{kHz}$. In addition, the resistance amplitude from pick to pick is about $550 \Omega$ for longitudinal crack and about $700 \Omega$ for transversal one.

In summary, we can confirm that the full inspection of rail head surface requires at least three sensors with a specific configuration. Therefore, the following section will be devoted to a study of the sensitivity of the proposed configuration as well as to a qualitative study of the calculated results. 

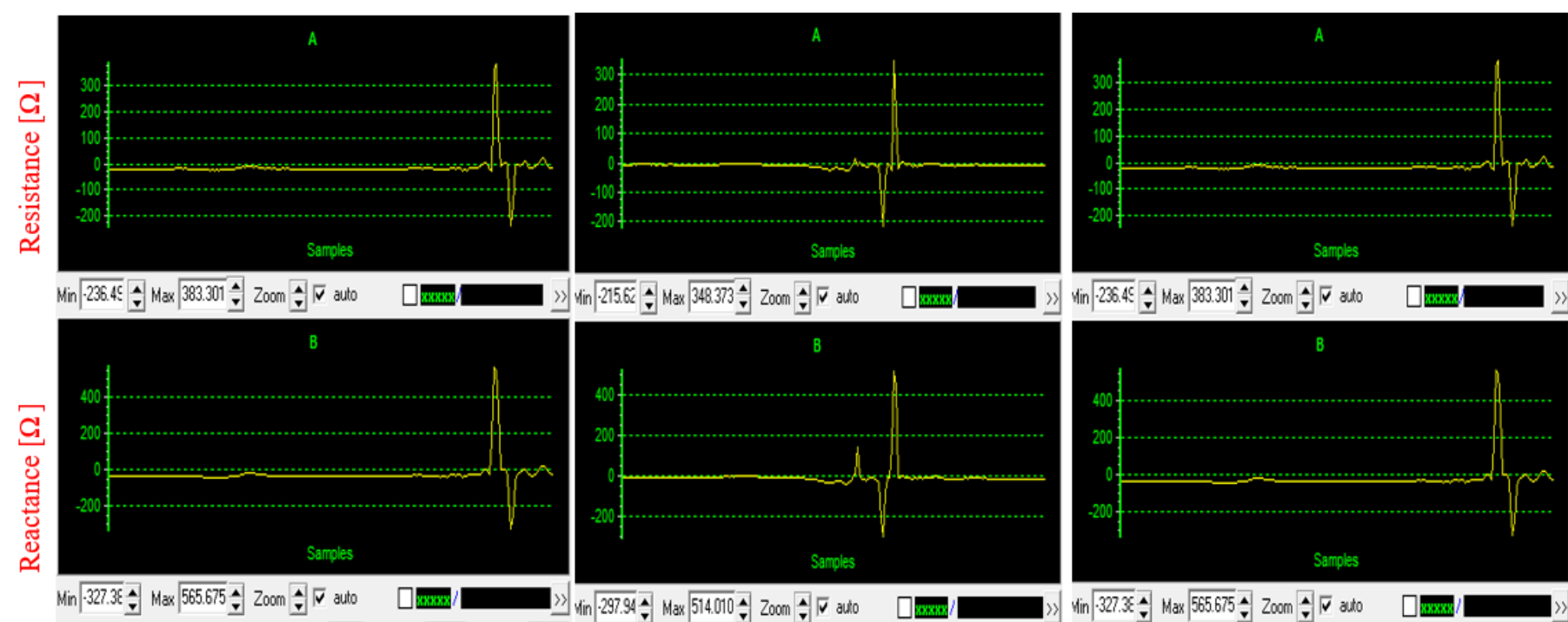

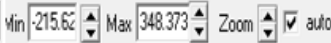

$\square$

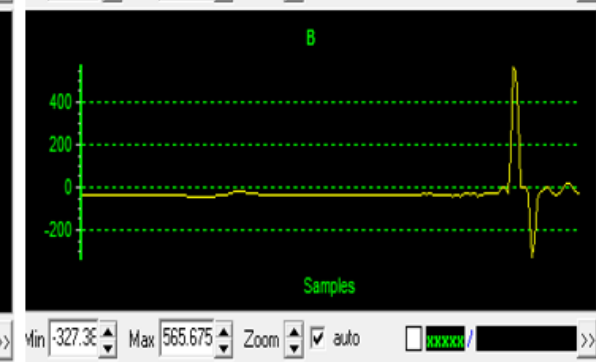

(a) $100 \mathrm{kHz}$

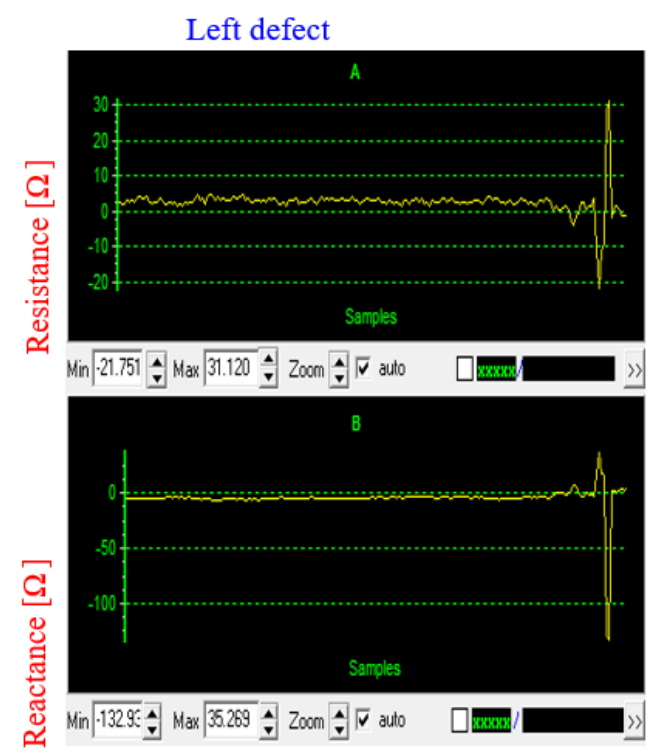

Midle defect

Right defect
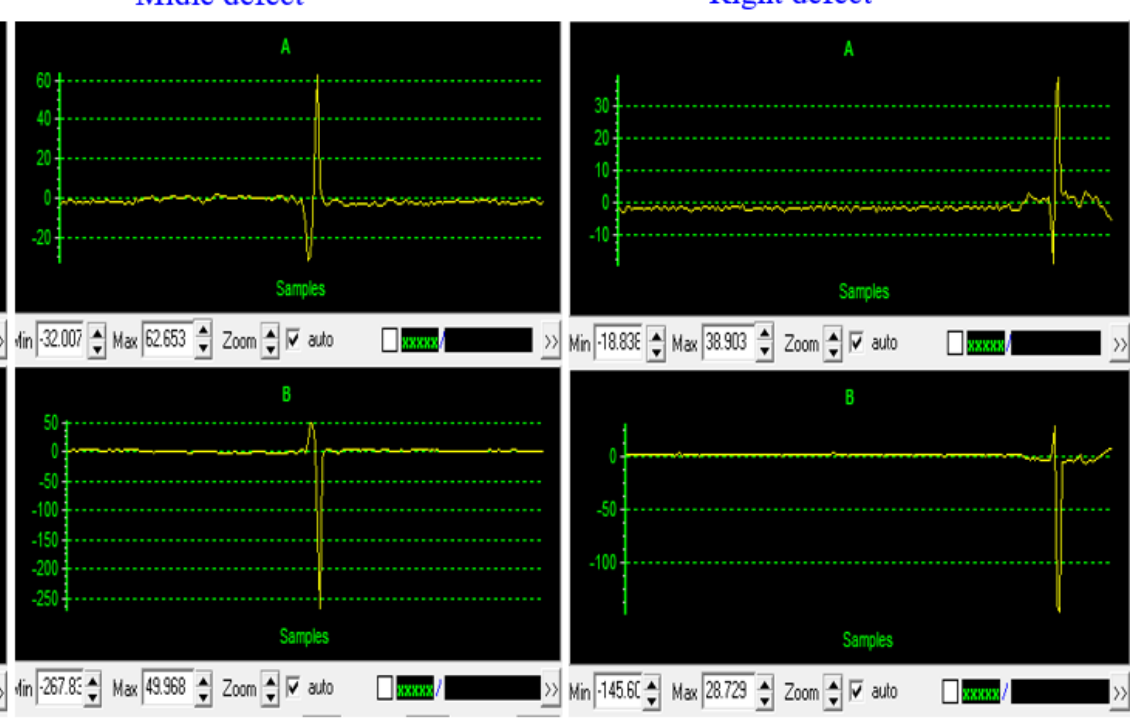

(b) $10 \mathrm{kHz}$

Figure 6. Resistance and reactance according to probe displacement for longitudinal cracks
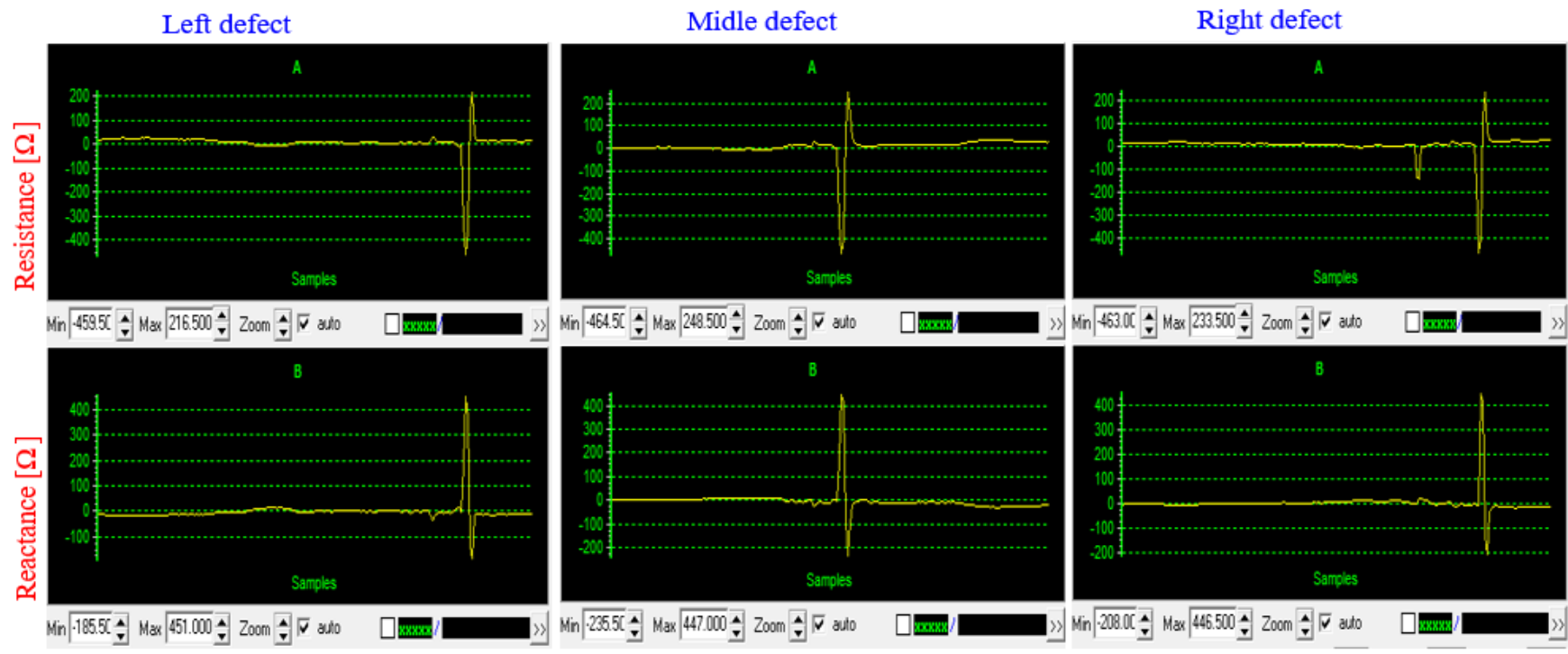

(a) $100 \mathrm{kHz}$ 

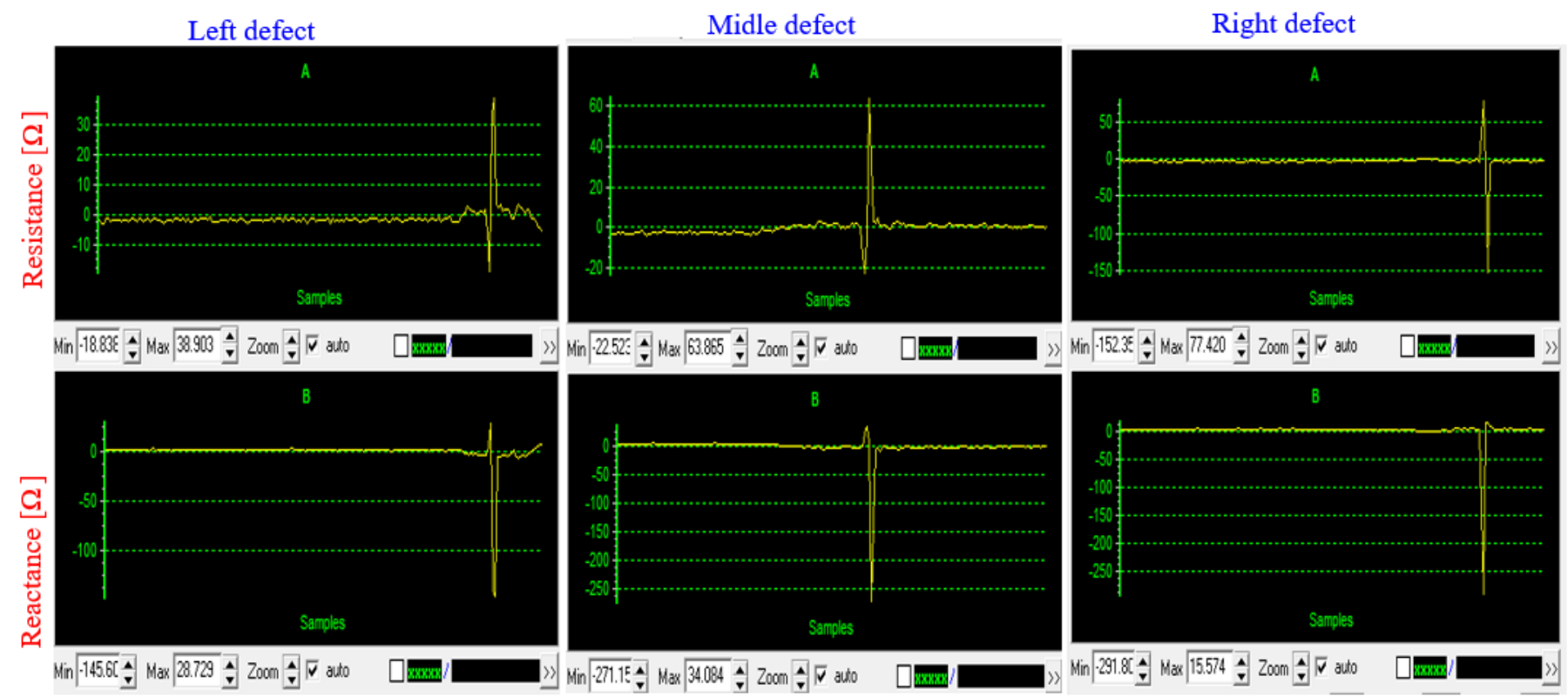

(b) $10 \mathrm{kHz}$

Figure 7. Resistance and reactance according to probe displacement for transverse cracks

\section{CHARECTERISTICS OF THE PROPOSED PROBE}

Differential coils have the advantage of being able to detect very small discontinuities and eliminate the external disruptions such as velocity, temperature and lift-off change. Hence, this sensor is more adapted to the detection of cracks in railway. The proposed multi-differentials system is constituted of six coils associated and placed following the $\mathrm{X}$ and $\mathrm{Z}$ axis as illustrated in Figure 8. To reduce the simulation time while preserving precision, our study will be based only on the top of the rail where defects often appear. The geometrical parameters and meshing are given in the figure below [8].

The physical and geometric characteristics of the system are given in Table 1.

Table 1. Physical and geometrical characteristics

\begin{tabular}{|c|c|}
\hline \multicolumn{2}{|c|}{ Coil } \\
\hline Outer radius $(\mathrm{mm})$ & 5 \\
\hline Inner radius (mm) & 2 \\
\hline Height (mm) & 5 \\
\hline Number of turns & 140 \\
\hline Lift-off (mm) & 3 \\
\hline Frequency $(\mathrm{kHz})$ & 100 \\
\hline \multicolumn{2}{|c|}{ Rail } \\
\hline Conductivity $(\mathrm{S} / \mathrm{m})$ & $4 \mathrm{e} 6$ \\
\hline $\begin{array}{c}\text { Relative } \\
\text { permeability }\end{array}$ & 25 \\
\hline Thickness $(\mathrm{mm})$ & 60 \\
\hline \multicolumn{2}{|c|}{ Defect } \\
\hline Length (mm) & 35 \\
\hline Depth (mm) & 5 \\
\hline Width (mm) & 5 \\
\hline
\end{tabular}

\section{MATHEMATICAL FORMULATION}

The electromagnetic phenomena involved in the nondestructive testing using a harmonic excitation source are covered by the magnetodynamic equation [10].

Indeed, it can be formulated in terms of magnetic potential $\mathrm{A}$ and scalar $\mathrm{V}$ on which it depends the source current density $\left(\mathrm{J}_{\text {source }}\right)$.

$$
\nabla^{2} A=\mu \sigma\left(\frac{\partial A}{\partial t}\right)-\mu J_{\text {SOURCE }}
$$

With the appropriate boundary conditions the potential A can be determined by solving the previous partial differential equation. The complexity of the studied problem imposes the use of the finite element method implemented on ComsolMultiphysics. Then, we deduce all the electrical quantities such as the impedance.

\section{RESULTS AND DISCUSSION}

Figures 9 and 10 depict the magnetic induction in each coil and the induced eddy current trajectory in the inspected U50 rail.

The defect signal is obtained while moving the probe according to $\mathrm{OZ}$ axis from $\mathrm{z}=10 \mathrm{~mm}$ to $\mathrm{z}=250 \mathrm{~mm}$ with a step of $1 \mathrm{~mm}$. In fact, the impedance variation components are shown in Figure 11.

We remark from the previous figures that the signal is constituted of three differential signals (A, B and C) corresponding to the passage of every differential sensor through the defect axis. Because in these points the induced current are strongly perturbed as illustrated in Figure 12. 


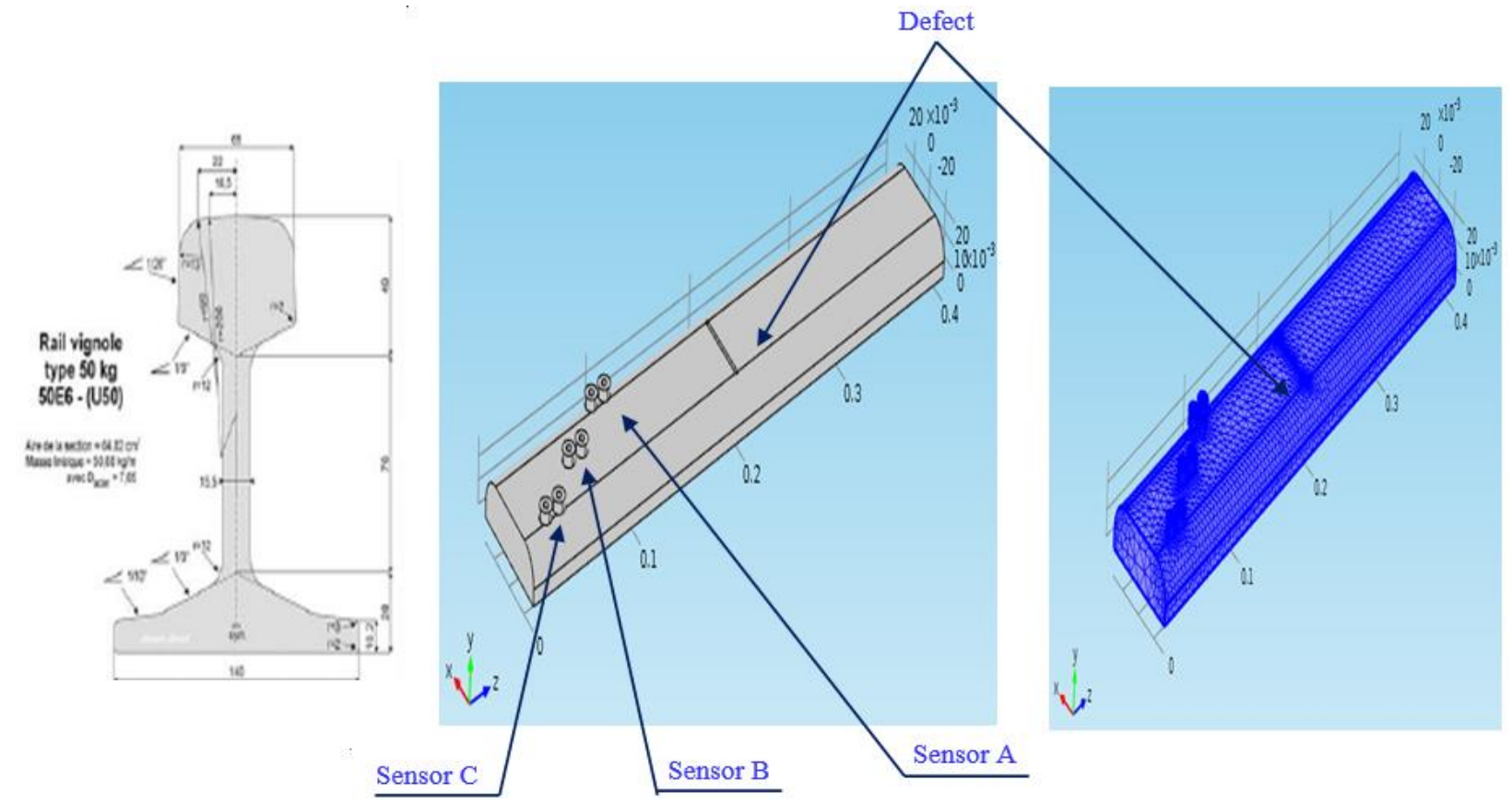

Figure 8. Geometrical configuration and meshing of the studied device

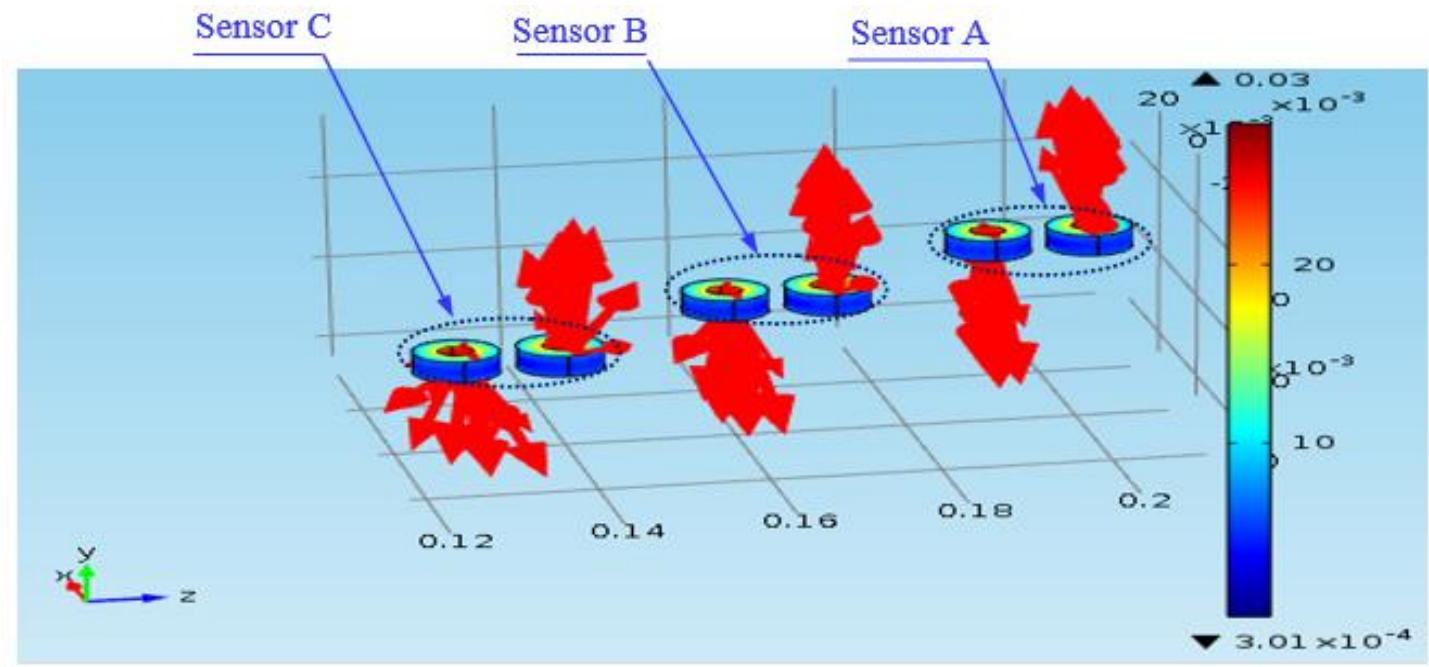

Figure 9. Magnetic induction in each coil

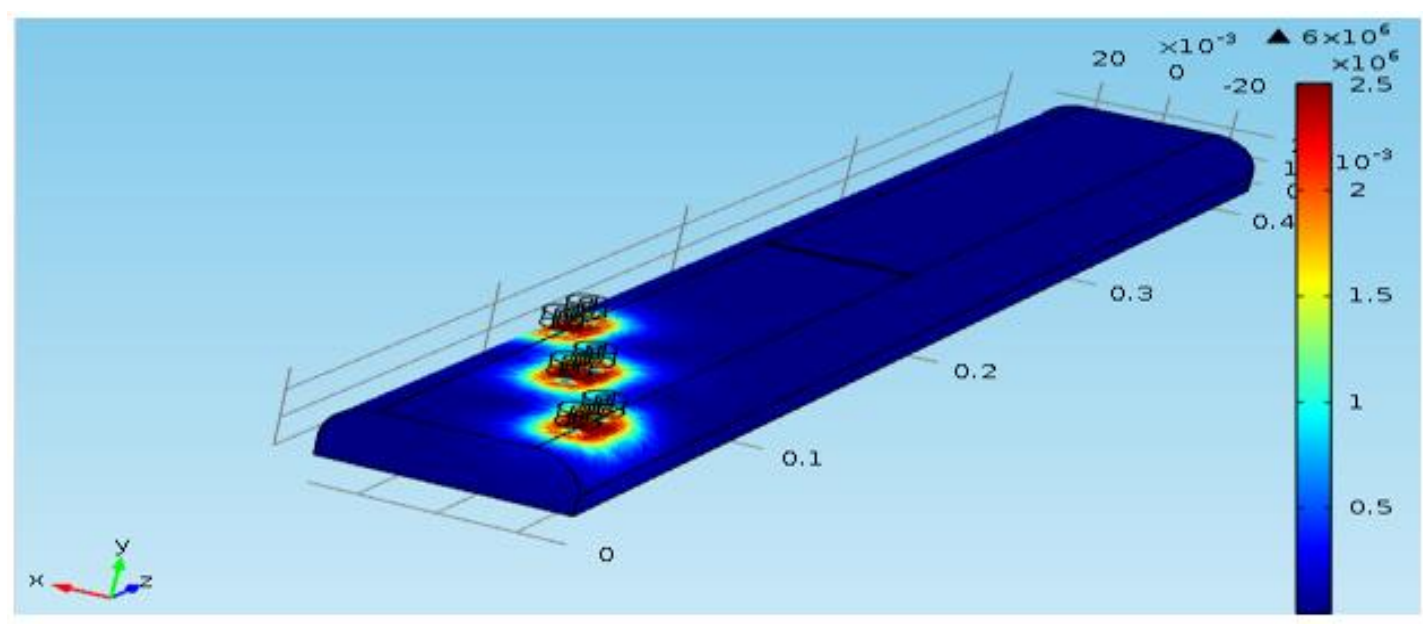

Figure 10. Carthographie of the current density when the defect is far from differential sensor (A), (B) and (C) respectively 


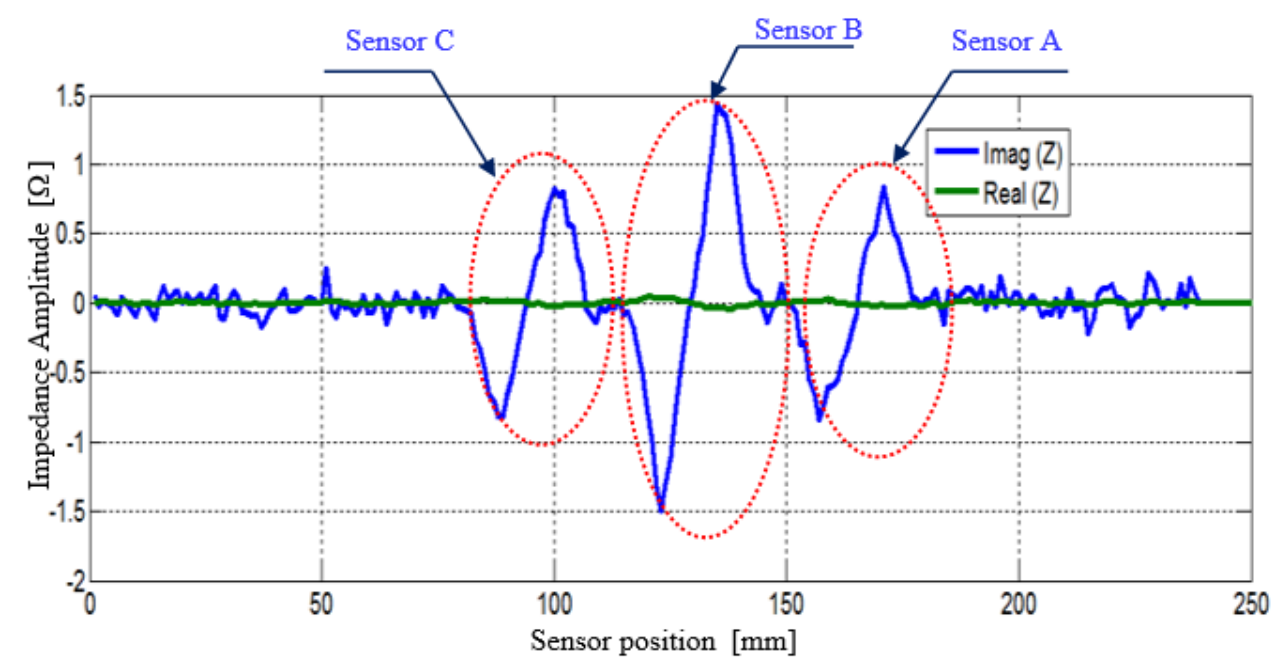

Figure 11. Impedance amplitude according to sensor position

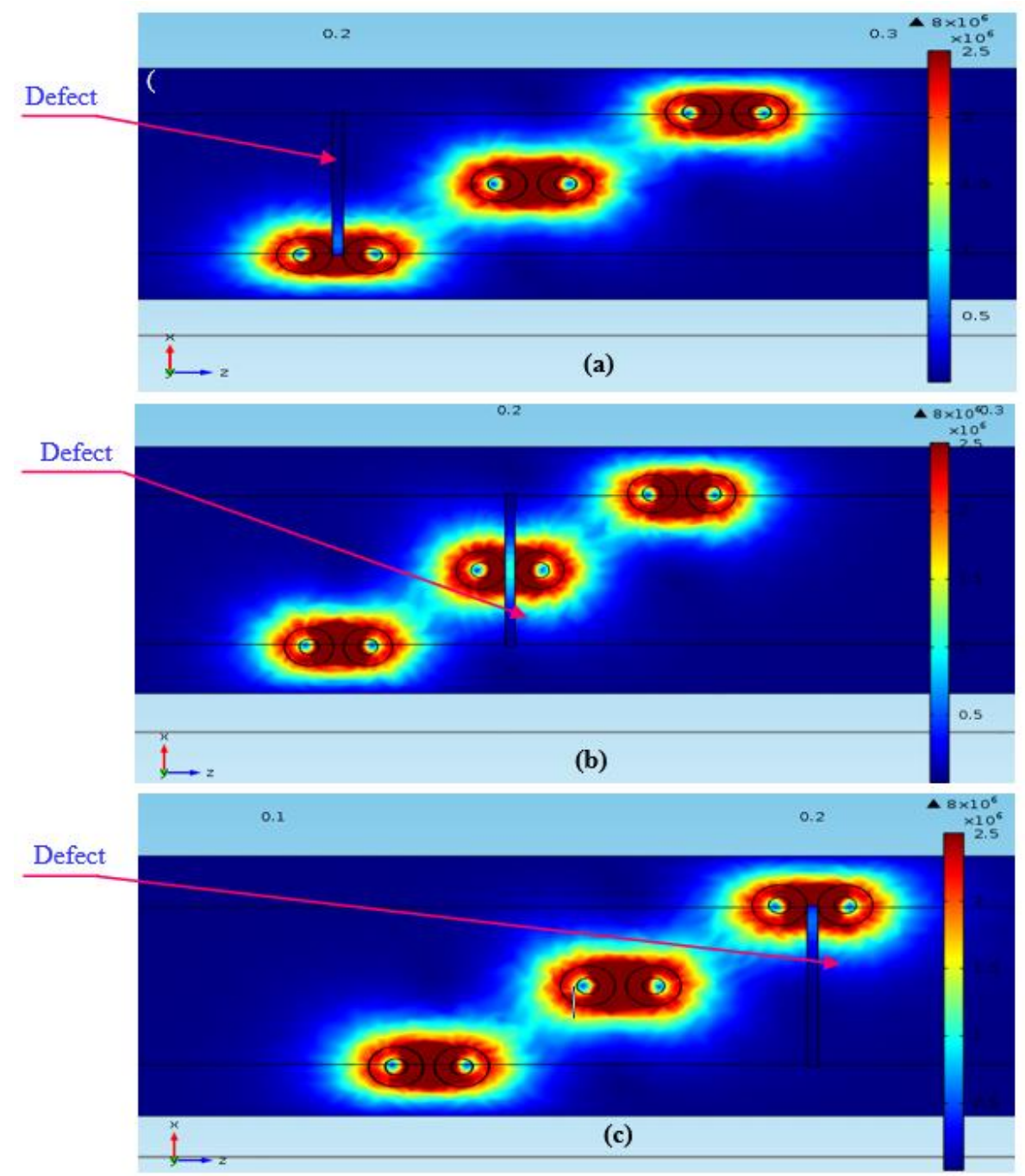

Figure 12. Carthographie of the current density when the defect is above differential sensors (A), (B) and (C)

\section{CONCLUSION}

In railway maintenance, the rail inspection is an important process. It is periodically inspected or maintained to avoid dangerous situations. Inspections are carried out manually by railway workers by usually walking along the track to determine the obstacles. Crack detection in rail is a strenuous issue and endeavor has been spent in the build out of dependable crack detection methods for use on inservice rails. Flaw detections are determined mainly by ultrasonic or eddy current methods [3]. In this work, after having presented the experimental eddy current nondestructive testing bench, we 
have exploited this system to measure the differential impedance of a signal probe (Blarow-D differential probe) operating on U50 rail surface in which transverse and longitudinal cracks are artificially printed. From the obtained results, we can conclude that the probe detects only the crack when it is positioned on its path.

From this study, we have demonstrated that the entire inspection of rail head surface requires at least three sensors with a specific configuration. The proposed multi-differentials system is constituted of three differential probes associated and placed following the $\mathrm{X}$ and $\mathrm{Z}$ as described above. In fact, the results showed the efficiency and the robustness of the proposed configuration in the detection of cracks regardless its size, orientation and location. As future work, in order to realize the automatic recognition of rail defect detection data by computer, the existing methods are mainly to select the features of rail flaw detection data manually, and then use relevant algorithms to recognize and classify from the perspective of image [12-15]. On the other hand, the effects of detection speed on eddy current testing (ECT) signals need to be investigated as well as the quantitative evaluation method of rail surface cracks at different speeds [16].

\section{REFERENCES}

[1] Liu, Y.Y., Fan, L.T., Zhang, S. (2018). Exploration of rail defect detection system. $20185^{\text {th }}$ International Conference on Information Science and Control Engineering (ICISCE), pp. 1118-1122. https://doi.org/10.1109/ICISCE.2018.00230

[2] Zhang, X., Gui, Y.M., Wang, Y., Sun, M.J., Hu, H.S. (2018). Hengshan Hu an improved AE detection method of rail defect based on multi-level ANC with VSS-LMS. Mechanical Systems and Signal Processing, 99: 420-433. https://doi.org/10.1016/j.ymssp.2017.06.029

[3] Heckel, T., Casperson, R., Rühe, S., Mook, G. (2018). Signal processing for non-destructive testing of railway tracks. AIP Conference Proceedings, 1949(1): 030005. https://doi.org/10.1063/1.5031528

[4] Rajamäki, J., Vippola, M., Nurmikolu, A., Viitala, T. (2018). Limitations of eddy current inspection in railway rail evaluation. Proceedings of the Institution of Mechanical Engineers Part F: Journal of Rail and Rapid Transit, 232(1): 121-129. https://doi.org/10.1177/0954409716657848

[5] Augustyniak, M., Borzyszkowski, P., Buława, M. (2019). Towards a universal method for predicting eddy-current sensor characteristics in the railway industry. Journal of Nondestructive Evaluation, 38(29): 1-10. https://doi.org/10.1007/s10921-019-0568-7

[6] Uchanin, V., Nardoni, G. (2019). Detection of cracks in ferrous steel structures: New innovative eddy current techniques. Procedia Structural Integrity, 16: 198-204. https://doi.org/10.1016/j.prostr.2019.07.041

[7] Maneesh Kumar, M., Murali, M.S., Saranya, M., Arun, S., Jayakrishnan, R.P. (2018). A survey on crack detection technique in railway track. 2018 Conference on Emerging Devices and Smart Systems (ICEDSS), Tiruchengode, pp. 269-272. https://doi.org/10.1109/ICEDSS.2018.8544319

[8] Oukhellou, L. (1997). Paramétrisation et classification de signaux en contrôle non destructif. application à la reconnaissance des défauts de rails par courants de foucault. Thèse de Doctorat, Université de Paris Sud Centre d'Orsay, France. https://tel.archivesouvertes.fr/tel-00006600/document.

[9] Chandran, P., Rantatalo, M., Odelius, J., Lind, H., Famurewa, S.M. (2019). Train-based differential eddy current sensor system for rail fastener detection. Measurement Science and Technology, 30(12): 1-13. https://doi.org/10.1088/1361-6501/ab2b24

[10] Santandrea, L., Le Bihan, Y. (2010). Using COMSOLMultiphysics in an eddy current non-destructive testing context. Article Scientifique, Laboratoire de Genie Electrique de Paris, CNRS, Supelec, Université ParisSud 11, UPMC, https://www.comsol.com/paper/download/63102/santan drea_paper.pdf.

[11] Song, Z.L., Tsutomu, Y., Hideki, S., Yasushi, T. (2011). Detection of damage and crack in railhead by using eddy current testing. Journal of Electromagnetic Analysis and Applications, 3(12): 546-550. https://doi.org/10.4236/jemaa.2011.312082

[12] Bouchalaa, T., Abdelhadi, B., Benoudjit, A. (2015). New contactless eddy current nondestructive methodology for electric conductivity measurement. Nondestructive Testing and Evaluation, 30(1): 63-73. https://doi.org/10.1080/10589759.2014.992431

[13] Xu, Q.H., Zhao, Q.J., Yu, G., Wang, L.G., Shen, T. (2020). Rail defect detection method based on recurrent neural network. Proceedings of the $39^{\text {th }}$ Chinese Control Conference, Shenyang, China, pp. 27-29. https://doi.org/10.23919/CCC50068.2020.9188823

[14] Liu, Y.Y., Fan, L.T., Zhang, S. (2018). Exploration of rail defects detection, (2018). $20185^{\text {th }}$ International Conference on Information Science and Control Engineering. IEEE Computer Society, pp. 1118-1122. https://doi.org/10.1109/ICISCE.2018.00230

[15] Abbassi, A., Bouchala, T., Abdou, A., Abdelhadi, B. (2020). Eddy current characterization of 3D crack by analyzing probe signal and using a fast algorithm search. Russian Journal of Nondestructive Testing, 56(5): 426434. https://doi.org/ 10.1134/S1061830920050022

[16] Xu, P., Zhu, C.L., Zeng, H.M., Wang, P. (2020). Rail crack detection and evaluation at high speed based on differential ECT system. Measurment, 166: 108152. https://doi.org/10.1016/j.measurement.2020.108152 